\title{
Purification and properties of an oxygen-evolving reaction center complex from photosystem II membranes
}

\author{
A simple procedure utilizing a non-ionic detergent and elevated ionic strength
}

\author{
Demetrios F. Ghanotakis and Charles F. Yocum \\ Division of Biological Sciences and Department of Chemistry, The University of Michigan, Ann Arbor, MI 48109-1048. \\ USA
}

Received 6 December 1985

\begin{abstract}
A method is reported for the isolation of a highly resolved oxygen-evolving photosystem II reaction center preparation. This preparation can be separated from the more complex photosystem II membranes isolated by the procedure of Berthold et al. [(1981) FEBS Lett. 134, 231-234] by use of octylglucopyranoside at elevated ionic strengths; the oxygen-evolving material can be collected by centrifugation at relatively low $g$ values $(40000 \times \mathrm{g})$ in yields estimated to be more than $80 \%$. This new preparation lacks the 17 and $23 \mathrm{kDa}$ extrinsic polypeptides; addition of calcium and chloride produces activities approaching $1000 \mu \mathrm{mol} \mathrm{O} / \mathrm{h}$ per $\mathrm{mg}$ chlorophyll. Although activity is maximal in the presence of 2,5 -dichloro-p-benzoquinone, the response of activity to ferricyanide and 3-(3,4-dichlorophenyl)-1,1-dimethylurea indicates that the reducing side of photosystem II has been modified in this new oxygen-evolving reaction center preparation.
\end{abstract}

\section{Oxygen evolution Photosystem II Polypeptide Reaction center}

\section{INTRODUCTION}

The isolation of PS II membranes by exposure of thylakoids to various detergents $[1-4]$ has advanced knowledge of the polypeptide composition of PS II and has also provided a means to understand better the relationship between certain of these polypeptides and sites of catalytic activity. Preparation of a PS II 'core' complex [5-7] has made it possible to identify certain hydrophobic polypeptides which bind catalysts of PS II photochemistry. More recently, Tang and Satoh

Abbreviations: Chl, chlorophyll; DCBQ, 2,5-dichlorop-benzoquinone; DCMU, 3-(3,4-dichlorophenyl)-1,1dimethylurea; LHC, light-harvesting complex; Mes, 4-morpholineethanesulfonic acid; OGP, 1-O-n-octyl- $\beta$ D-glucopyranoside; PS, photosystem; RC, reaction center
[8], Satoh et al. [9] and Ikeuchi et al. [10] isolated oxygen-evolving RC complexes from PS II membranes which were further solubilized by use of non-ionic detergents such as digitonin or OGP. Ikeuchi et al. [10] used a sucrose density gradient of OGP-solubilized PS II membranes, whereas Satoh et al. [9] used a combination of density gradient centrifugation followed by two-step column chromatographic separation. In all cases, the isolated RC complex was depleted of two watersoluble polypeptides (17 and $23 \mathrm{kDa}$ ) and thus required the presence of non-physiological concentrations of $\mathrm{Ca}^{2+}$ and $\mathrm{Cl}^{-}$in order to retain oxygenevolution activity $[9,10]$.

Here, we report a new method for isolation of an oxygen-evolving PS II RC complex. This method does not require ultracentrifugation, sucrose density gradients or chromatographic separations and produces an oxygen-evolving RC complex in high yields. 


\section{MATERIALS AND METHODS}

Subchloroplast membranes, free of PS I and having high rates of oxygen evolution, were prepared as described in [2]. PS II membranes were solubilized with $35 \mathrm{mM}$ OGP, $0.4 \mathrm{M}$ sucrose, $50 \mathrm{mM}$ Mes, $\mathrm{pH} 6.0,10 \mathrm{mM} \mathrm{CaCl}_{2}$ and 0.5 or $1 \mathrm{M}$ $\mathrm{NaCl}$ at a Chl concentration of $1.5 \mathrm{mg} / \mathrm{ml}$. After incubation for $15 \mathrm{~min}$ in ice one part of the PS II membrane suspension was mixed with two parts of a solution containing $0.4 \mathrm{M}$ sucrose, $50 \mathrm{mM}$ Mes, pH $6.0,10 \mathrm{mM} \mathrm{CaCl}_{2}$ and 0.5 or $1 \mathrm{M} \mathrm{NaCl}$; mixing was followed by $90 \mathrm{~min}$ centrifugation at $40000 \times g$, and the resulting pellet was resuspended in a solution containing $0.4 \mathrm{M}$ sucrose, $50 \mathrm{mM}$ Mes, $\mathrm{pH} 6.0$, and $10 \mathrm{mM} \mathrm{NaCl}$ (fraction $\mathrm{A}$ ). The supernatant was desalted by $90 \mathrm{~min}$ dialysis against a solution containing $0.4 \mathrm{M}$ sucrose, $50 \mathrm{mM}$ Mes, pH 6.0 , and $10 \mathrm{mM} \mathrm{CaCl}_{2}$, further diluted by $25 \%$ using the dialysis medium, and subsequently centrifuged for $90 \mathrm{~min}$ at $40000 \times \mathrm{g}$. The pellet which resulted from this centrifugation step was resuspended in a medium containing $0.4 \mathrm{M}$ sucrose, $50 \mathrm{mM}$ Mes, $\mathrm{pH} 6.0$, and $10 \mathrm{mM}$ $\mathrm{CaCl}_{2}$ (fraction $\mathrm{B}$ ); the colorless supernatant was discarded. $\mathrm{Ca}^{2+}$ and $\mathrm{Cl}^{-}$-free samples were prepared by further dialysis of the above samples against a medium containing $0.4 \mathrm{M}$ sucrose and $50 \mathrm{mM}$ Mes, pH 6.0.

Gel electrophoresis was carried out as in [11] with the modification that a $15 \%$ acrylamide resolving gel was used and $6 \mathrm{M}$ urea was present in the gel; $\mathrm{O}_{2}$ evolution was measured with a Clarktype oxygen electrode. EPR spectroscopy was carried out on a Bruker ER-200D spectrometer operated at X-band and interfaced to a Nicolet 1180 computer.

\section{RESULTS}

As shown in fig. 1, the pellet (fraction A) isolated from the first centrifugation of the procedure described in section 2 consists mainly of the LHC (lanes 3,5), whereas the final pellet (fraction B) contains a complex which has been depleted of the LHC and several other polypeptides (lanes 2,6). Even though the presence of $1 \mathrm{M} \mathrm{NaCl}$ during exposure to the detergent results in the quantitative isolation of a PS II RC complex, it also releases the water-soluble $33 \mathrm{kDa}$ polypeptide and thus af-

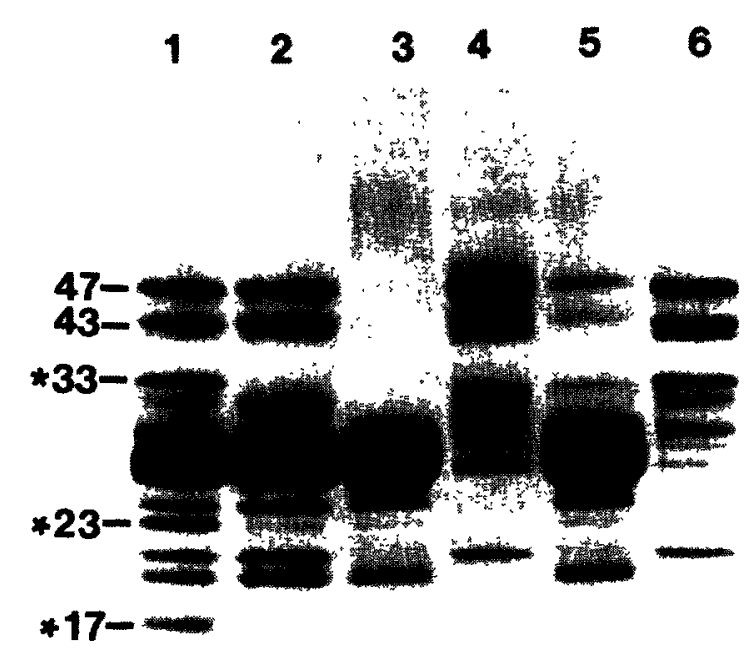

Fig.1. Gel clectrophoresis patterns of (1) untreated PS II membranes; (2) Tris-treated $(0.8 \mathrm{M}, \mathrm{pH} 8.0)$ PS II membranes; (3) fraction A prepared by exposure of PS II membranes to $35 \mathrm{mM}$ OGP plus $1 \mathrm{M} \mathrm{NaCl}$; (4) fraction B prepared as in (3); (5) fraction A prepared by exposure of PS II membranes to $35 \mathrm{mM}$ OGP plus $0.5 \mathrm{M} \mathrm{NaCl}$; (6) fraction B prepared as in (5). Asterisk: water-soluble extrinsic polypeptides.

fects oxygen-evolution activity. On the other hand, the presence of $0.5 \mathrm{M} \mathrm{NaCl}$ during solubilization results in a preparation which retains the $33 \mathrm{kDa}$ protein and shows high oxygen-evolution activity (table 1). In contrast to the preparation reported by Ikeuchi et al. [10], this PS II RC complex is very active in the presence of DCBQ as an electron acceptor (table 1); $\mathrm{Fe}(\mathrm{CN}){ }_{6}^{3-}$ appears to be a more effective acceptor in this new preparation when compared to control PS II membranes but is not as effective as DCBQ (table 1). As shown in table 1, oxygen-evolution activity of the PS II RC complex is sensitive to DCMU addition. The observation that $\mathrm{Fe}(\mathrm{CN})_{6}^{3-}$ is a relatively effective acceptor in this complex as well as the fact that DCMU is not as inhibitory as in control PS II membranes suggest that some changes have taken place at the 
Table 1

Oxygen-evolution activity of intact PS II membranes and the PS II RC complex in the presence of various acceptor systems

\begin{tabular}{lcc}
\hline Additions & \multicolumn{2}{c}{ Activity $\left(\mu \mathrm{mol} \mathrm{O}_{2} / \mathrm{mg} \text { Chl per h }\right)^{\mathrm{a}}$} \\
\cline { 2 - 3 } & PS II membranes & PS II RC complex \\
\hline DCBQ $(500 \mu \mathrm{M})$ & 640 & 940 \\
Fe(CN) ${ }^{3-}(2 \mathrm{mM})$ & 140 & 530 \\
DCBQ $(500 \mu \mathrm{M})+\mathrm{Fe}(\mathrm{CN})_{6}^{3-}(2 \mathrm{mM})$ & 600 & 900 \\
DCBQ $(500 \mu \mathrm{M})+\operatorname{DCMU}(5 \mu \mathrm{M})$ & 0 & 230 \\
Fe(CN) $)_{6}^{3-}(2 \mathrm{mM})+\operatorname{DCMU}(5 \mu \mathrm{M})$ & 20 & 190 \\
\hline
\end{tabular}

${ }^{a}$ Assay medium: $50 \mathrm{mM}$ Mes, $\mathrm{pH} 6.0$, and $10 \mathrm{mM} \mathrm{CaCl}_{2}$

reducing side of PS II. Since the main difference, in terms of polypeptide content, between our preparation and that of Ikeuchi et al. [10] is a polypeptide of approx. $20 \mathrm{kDa}$ (fig.1, lane 6), it is possible that this species is involved in some function on the reducing side of PS II. An examination of the manganese content of the PS II RC complex
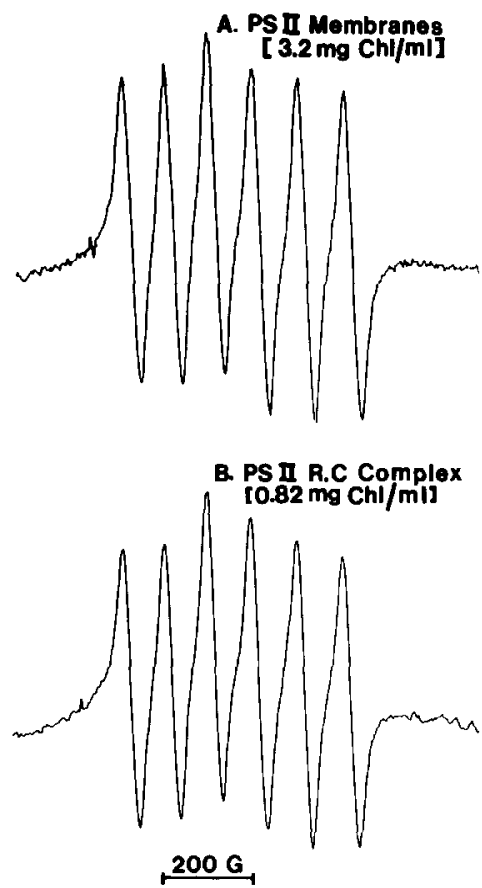

Fig.2. EPR signal of hexa-aquo $\mathrm{Mn}$ in (A). PS II membranes and (B) the PS II RC complex, both acidified with $\mathrm{HClO}_{4}$. Instrumental conditions: microwave power, $64 \mathrm{~mW}$; modulation amplitude, $32 \mathrm{Gpp}$; gain, $4 \times 10^{5}$; time constant, $200 \mathrm{~ms}$. is shown in fig.2. Acidification of PS II membranes and the PS II RC complex reveals that the latter shows a 3.7-fold $\mathrm{Mn}$ enrichment on a $\mathrm{Chl}$ basis. A quantitation of $\mathrm{Z}^{+}$, the primary donor to P680, in Tris-treated preparations of the PS II RC complex also revealed a 3.7-fold enrichment, on a Chl basis, when compared to Tris-treated PS II membranes (not shown). As shown in the gel of fig.1, the PS II RC complex has been depleted of the water-soluble 17 and $23 \mathrm{kDa}$ polypeptides; it is known that under these conditions, nonphysiological concentrations of $\mathrm{Cl}^{-}$and $\mathrm{Ca}^{2+}$ are required for oxygen-evolution activity [12-16]. Fig. 2 shows the $\mathrm{Cl}^{-}$requirement of the PS II RC complex, while fig. 3 shows a $\mathrm{Ca}^{2+}$ titration in the presence of sufficient $\mathrm{Cl}^{-}(15 \mathrm{mM} \mathrm{NaCl})$. The titrations of figs 3 and 4 clearly demonstrate the in-

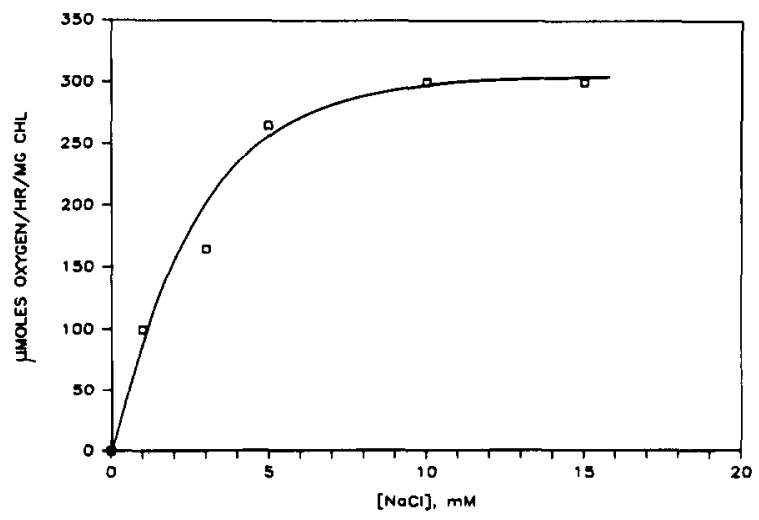

Fig.3. Rates of oxygen evolution of the PS II RC complex as a function of added $\mathrm{NaCl}$. Assay medium: $50 \mathrm{mM}$ Mes, $\mathrm{pH} 6.0,500 \mu \mathrm{M}$ DCBQ and the indicated concentration of $\mathrm{NaCl}(7 \mu \mathrm{g} \mathrm{Chl} / \mathrm{ml})$. Each point is the average of 2 measurements. Variation was less than $5 \%$. 


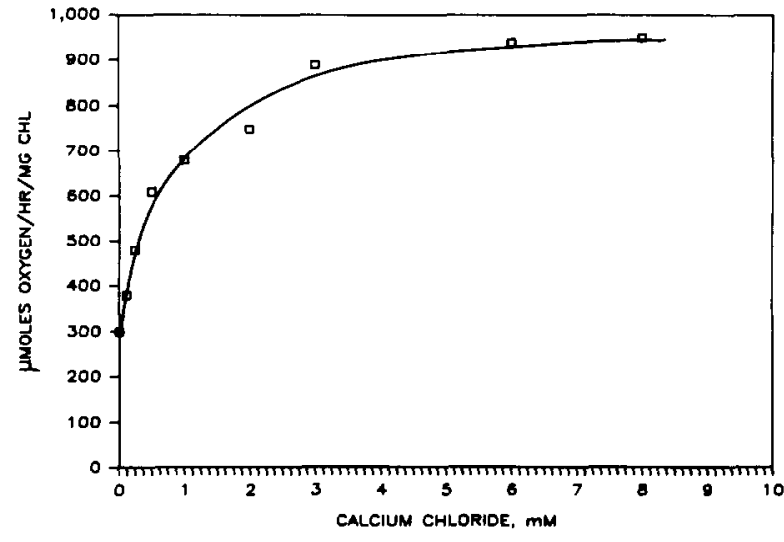

Fig.4. Rates of oxygen evolution of the PS II RC complex as a function of added $\mathrm{CaCl}_{2}$. Assay medium: $50 \mathrm{mM}$ Mes, pH $6.0,15 \mathrm{mM} \mathrm{NaCl}, 500 \mu \mathrm{M}$ DCBQ and the indicated concentration of $\mathrm{CaCl}_{2}(7 \mu \mathrm{g} \mathrm{Chl} / \mathrm{ml})$. Other conditions as in fig.3.

volvement of both $\mathrm{Ca}^{2+}$ and $\mathrm{Cl}^{-}$in oxygenevolution activity. Since Ikeuchi et al. [10] reported that addition of digitonin in the assay medium enhanced oxygen-evolution activity by a factor of 1.5, we added digitonin to our assay system, but observed no stimulation of activity (not shown).

\section{DISCUSSION}

In this communication we have reported a very simple procedure for the isolation of an active PS II RC complex. Our procedure does not involve ultracentrifugation, sucrose density gradients or chromatographic separation; a simple ex- posure to the detergent OGP in the presence of high ionic strength followed by selective manipulation of the detergent and salt concentrations results in separation of the PS II membranes into two complexes. One of these consists mainly of the LHC whereas the other contains the hydrophobic polypeptides of the core complex as well as the water-soluble $33 \mathrm{kDa}$ polypeptide, a $10 \mathrm{kDa}$ polypeptide [17] and a species with a molecular mass estimated to be $20 \mathrm{kDa}$ in our gel electrophoresis system. The presence of high concentrations of $\mathrm{NaCl}$ in the isolation procedure reported here has two effects. First, it promotes aggregation of the LHC $[18,19]$, and second, it facilitates the dissociation of the PS II RC complex from the rest of the photosynthetic membrane.

It is instructive to compare this new oxygenevolving PS II RC complex with the preparation described by Ikeuchi et al. [10]. As the data of table 2 demonstrate, both preparations effect an enrichment in manganese of about 3.7-fold on a Chl basis; for the present preparation, this enrichment is also observed for $\mathrm{Z}^{+}$, suggesting that no loss of manganese has occurred during the enrichment process. We also note that for our preparation, the manganese is EPR-silent at room temperature. Inspection of table 2 also shows that both preparations are capable of oxygen-evolution activity with rates which exceed $900 \mu \mathrm{mol} \mathrm{O}_{2} / \mathrm{h}$ per $\mathrm{mg} \mathrm{Chl}$. Differences in the conditions necessary for this activity are shown in table 2 . The preparation of Ikeuchi et al. [10] operates most efficiently with ferricyanide as the PS II acceptor in a DCMU-

Table 2

Properties of oxygen-evolving PS II RC complexes

\begin{tabular}{|c|c|c|c|c|c|c|}
\hline \multirow{2}{*}{$\begin{array}{l}\text { PS II RC complex } \\
\text { prepared } \\
\text { according to: }\end{array}$} & \multicolumn{2}{|c|}{$\begin{array}{l}\text { Component enrichment } \\
\text { on a Chl basis }{ }^{\mathrm{a}}\end{array}$} & \multicolumn{2}{|c|}{$\begin{array}{l}\text { Activity }\left(\mu \mathrm{mol} \mathrm{O} \mathrm{O}_{2} / \mathrm{mg}\right. \\
\text { Chl per h) }\end{array}$} & \multirow[t]{2}{*}{$\begin{array}{l}\text { DCMU }(5 \mu \mathrm{M}) \\
\text { sensitivity }\end{array}$} & \multirow{2}{*}{$\begin{array}{l}\text { Detergent required } \\
\text { for optimal } \\
\text { activity }\end{array}$} \\
\hline & Mn & $\mathrm{z}$ & $+\mathrm{Fe}(\mathrm{CN})_{6}^{3}$ & $+\mathrm{DCBQ}$ & & \\
\hline This paper & 3.7 & 3.7 & 530 & 940 & $\begin{array}{l}80 \% \text { sensitive } \\
20 \% \text { insensitive }\end{array}$ & no \\
\hline Ikeuchi et al. [10] & 3.7 & - & 846 & 461 & insensitive & yes \\
\hline
\end{tabular}

a The PS II RC complex was compared to PS II membranes prepared by exposure of thylakoids to Triton X-100

${ }^{b}$ Assay medium contained $\mathrm{CaCl}_{2}$ 
insensitive reaction. The material produced by our procedure is optimally active in the presence of DCBQ and this activity is sensitive to DCMU (see also table 1). This new oxygen-evolving PS II RC complex has the advantage that its reducing side is relatively intact and moreover does not require the presence of a detergent for maximum activity. It is possible that the observation of Ikeuchi et al. [10] that their PS II preparation does not require DCBQ may derive from the requirement, in their preparation, for digitonin to produce enhanced rates of oxygen-evolution activity. A common property of both preparations is that in spite of substantial enhancements of components (manganese, $Z$ ) associated with the oxidizing side of PS II and the oxygen-evolving complex, oxygen-evolution activity is not comparably enriched. The explanation for this observation is unclear, but may relate to subtle changes in the reducing side of PS II, loss of LHC or both of these factors and other considerations which are not obvious at present. The enrichment in manganese content of $\mathrm{O}_{2}$-evolving $\mathrm{RC}$ preparations provides a very attractive system for spectroscopic characterization of the oxidizing side of PS II. These studies, an immunological characterization of the various polypeptides of this oxygen-evolving RC PS II complex, and further experiments to improve oxygen-evolution activity are now in progress.

\section{ACKNOWLEDGEMENTS}

We wish to thank Dr G.T. Babcock for helpful discussions. This research was supported by grants to C.F.Y. from the National Science Foundation (PCM82-14240) and the Competitive Research Grants Office of USDA (G-82-1-1127).

\section{REFERENCES}

[1] Berthold, D.A., Babcock, G.T. and Yocum, C.F. (1981) FEBS Lett. 134, 231-234.

[2] Ghanotakis, D.F., Babcock, G.T. and Yocum, C.F. (1984) Biochim. Biophys. Acta 765, 388-398.

[3] Yamamoto, Y., Doi, M., Tamura, M. and Nishimura, M. (1981) FEBS Lett. 133, 265-268.

[4] Kuwabara, T. and Murata, N. (1982) Plant Cell Physiol. 23, 533-539.

[5] Satoh, K., Nakatani, H.Y., Steinback, K.E., Watson, J. and Arntzen, C.J. (1983) Biochim. Biophys. Acta 724, 142-150.

[6] Diner, B.A. and Wollman, F.A. (1980) Eur. J. Biochem. 110, 521-526.

[7] Gounaris, K. and Barber, J. (1985) FEBS Lett. 188, 68-72.

[8] Tang, X.-S. and Satoh, K. (1985) FEBS Lett. 179, 60-64.

[9] Satoh, K., Ohno, T. and Katoh, S. (1985) FEBS Lett. 180, 320-330.

[10] Ikeuchi, M., Yuasa, M. and Inoue, Y. (1985) FEBS Lett. 185, 316-322.

[11] Chua, N.H. (1980) Methods Enzymol. 69, 434-446.

[12] Ghanotakis, D.F., Topper, J.N., Babcock, G.T. and Yocum, C.F. (1984) FEBS Lett. 170, 169-173.

[13] Ghanotakis, D.F., Babcock, G.T. and Yocum, C.F. (1985) FEBS Lett. 192, 1-3.

[14] Akabori, K., Imaoka, A. and Toyoshima, V. (1984) FEBS Lett. 173, 36-40.

[15] Andersson, B., Critchley, C., Ryrie, I.J., Jansson, C., Larsson, C. and Anderson, J.M. (1984) FEBS Lett. $168,113-117$.

[16] Murata, N. and Miyao, M. (1985) Trends Biochem. Sci. 10, 122-124.

[17] Ljungberg, V., Ảkerlund, H.-E. and Andersson, B. (1984) FEBS Lett. 175, 255-258.

[18] Rubin, B.T., Chow, W.S. and Barber, J. (1981) Biochim. Biophys. Acta 634, 174-190.

[19] Mullet, J.E. and Arntzen, C.J. (1980) Biochim. Biophys. Acta 589, 100-117. 